\title{
Prática de governança e gestão técnica da assistência farmacêutica no Município de
}

\section{Xinguara, Pará}

Practice of governance and technical management of pharmaceutical care in the Municipality of Xinguara, Pará

Práctica de gobernanza y gestión técnica de la atención farmacéutica en el Municipio de Xinguara, Pará

Recebido: 29/03/2021 | Revisado: 08/04/2021 | Aceito: 09/04/2021 | Publicado: 20/04/2021

\author{
Renata Lima Ferreira \\ ORCID: https://orcid.org/0000-0002-4094-4511 \\ Prefeitura Municipal de Xinguara, Brasil \\ E-mail: renatafely@hotmail.com \\ Orenzio Soler \\ ORCID: https://orcid.org/0000-0003-2246-0019 \\ Universidade Federal do Pará, Brasil \\ E-mail: orenziosoler@gmail.com
}

\begin{abstract}
Resumo
Objetivo: Investigar a prática de governança e gestão técnica da assistência farmacêutica no município de Xinguara, Pará. Métodos: Trata-se de um estudo de caso, ocorrido entre julho de 2018 e junho de 2019, fundamentado na Pesquisa-Ação e na Triangulação de Métodos, sobre o processo de governança e gestão técnica da assistência farmacêutica. Resultados: Apresenta-se evidências sobre tipos de intervenções que asseguram uma melhor qualidade da assistência farmacêutica, os desfechos da oficina de planejamento estratégico situacional, o cumprimento de indicadores relacionados as práticas de governança, indicadores relacionados instrumentos de planejamento e gestão, gestão técnica da assistência farmacêutica, gestão clínica do medicamento, políticas setoriais e cumprimento de indicadores relacionados a logística da assistência farmacêutica. Conclusão: Infere-se a necessidade do planejamento municipal explicitar as ações de assistência farmacêutica articuladas à coordenação técnica de assistência farmacêutica e vinculadas aos instrumentos de gestão. Preconiza-se intervenções farmacêuticas que fortaleçam a governança e a gestão técnica da assistência farmacêutica no município de Xinguara, Pará.
\end{abstract}

Palavras-chave: Saúde pública; Governança; Gestão em saúde; Assistência farmacêutica; Medicamentos.

\begin{abstract}
Objective: To investigate the practice of governance and technical management of pharmaceutical assistance in the municipality of Xinguara, Pará. Methods: This is a Case Study, which took place between July 2018 and June 2019, based on Action Research and the Triangulation of Methods, on the governance process and technical management of pharmaceutical assistance. Results: Evidence is presented on types of interventions that ensure a better quality of pharmaceutical assistance, the outcomes of the situational strategic planning workshop, compliance with indicators related to governance practices, indicators related to planning and management instruments, technical management of assistance pharmaceutical, clinical medicine management, sectoral policies and compliance with indicators related to pharmaceutical assistance logistics. Conclusion: It is inferred the need for municipal planning to make explicit the pharmaceutical assistance actions linked to the technical coordination of pharmaceutical assistance and linked to the management instruments. Pharmaceutical interventions are recommended to strengthen the governance and technical management of pharmaceutical assistance in the municipality of Xinguara, Pará.
\end{abstract}

Keywords: Public health; Governance; Health management; Pharmaceutical assistance; Medicines.

\section{Resumen}

Objetivo: Investigar la práctica de gobernanza y gestión técnica de la asistencia farmacéutica en el municipio de Xinguara, Pará. Métodos: Este es un Estudio de Caso, que se llevó a cabo entre julio de 2018 y junio de 2019, basado en Investigación Acción y Triangulación de Métodos, sobre el proceso de gobernanza y gestión técnica de la asistencia farmacéutica. Resultados: Se presenta evidencia sobre tipos de intervenciones que aseguran una mejor calidad de la asistencia farmacéutica, los resultados del taller de planificación estratégica situacional, el cumplimiento de los indicadores relacionados con las prácticas de gobernanza, los indicadores relacionados con los instrumentos de planificación y gestión, la gestión técnica de la asistencia farmacéutica, clínica. gestión de medicamentos, políticas sectoriales y cumplimiento de indicadores relacionados con la logística de asistencia farmacéutica. Conclusión: Se 
infiere la necesidad de una planificación municipal para explicar las acciones de asistencia farmacéutica vinculadas a la coordinación técnica de la asistencia farmacéutica y vinculadas a los instrumentos de gestión. Se recomiendan intervenciones farmacéuticas para fortalecer la gobernanza y la gestión técnica de la asistencia farmacéutica en el municipio de Xinguara, Pará.

Palabras clave: Salud pública; Gobernanza; Gestión sanitaria; Asistencia farmacéutica; Medicinas.

\section{Introdução}

A assistência farmacêutica trata de um conjunto de ações voltadas à promoção, proteção e recuperação da saúde, tanto individual como coletivo, tendo o medicamento como insumo essencial e visando o acesso e ao seu uso racional. Este conjunto envolve a pesquisa, o desenvolvimento e a produção de medicamentos e insumos, bem como a sua seleção, programação, aquisição, distribuição, dispensação, garantia da qualidade dos produtos e serviços, acompanhamento e avaliação de sua utilização, na perspectiva da obtenção de resultados concretos e da melhoria da qualidade de vida da população (Brasil, 2004).

A assistência farmacêutica envolve ações referentes ao cuidado farmacêutico, considerado modelo de prática farmacêutica, desenvolvida no contexto da Atenção Primária a Saúde, Média e Alta Complexidade. Compreende atitudes, valores éticos, comportamentos, habilidades, compromissos e corresponsabilidades na prevenção de doenças, promoção e recuperação da saúde, de forma integrada à equipe de saúde. Trata-se da interação direta do farmacêutico com o usuário, visando uma farmacoterapia racional e a obtenção de resultados definidos e mensuráveis, voltados para a melhoria da qualidade de vida. Esta interação também deve envolver as concepções dos seus sujeitos, respeitadas as suas especificidades biopsicossociais, sob a ótica da integralidade das ações de saúde (Brasil, 2004).

Nesse sentido, faz-se necessário que os serviços farmacêuticos estejam organizados, estruturados e integrados aos demais serviços de saúde, tendo como foco garantir a disponibilidade de medicamentos, assim como a qualidade e conservação. Ainda no contexto dos serviços farmacêuticos é importante prestar serviços assistenciais, com foco na efetividade e na segurança da terapêutica: avaliar, obter e difundir informações sobre medicamentos e sobre saúde na perspectiva da educação em saúde e da educação permanente das equipes (Brasil, 2020).

As ações de qualificação da assistência farmacêutica são imprescindíveis para a sustentabilidade; em especial, aquelas relacionadas a assegurar a efetividade de medicamentos e a eficiência de tratamentos (Soler et al., 2018). Nesta perspectiva, reconhece-se a necessidade da Assistência Farmacêutica estar explícita e vinculada aos instrumentos de gestão do Sistema Único de Saúde (SUS); em especial, ao Plano Municipal de Saúde (PMS), Programação Anual de Saúde (PAS) e ao Relatório Anual de Gestão (RAG) e a Programação Geral das Ações e Serviços de Saúde (PGASS). Nesta perspectiva, o objetivo do trabalho foi investigar a prática de governança e gestão técnica da assistência farmacêutica no município de Xinguara, Pará; ou seja, a institucionalização da assistência farmacêutica.

\section{Metodologia}

Trata-se de um Estudo de Caso (Freitas \& Jabbour, 2011; Minayo, 2012; Yin, 2015), ocorrido entre julho de 2018 e junho de 2019, fundamentado na Pesquisa-Ação (Mallmann, 2015; Mucci \& Mafra, 2016) e na Triangulação de Métodos (Marcondes \& Brisola, 2014; Paranhos et al., 2016) sobre o processo de gestão técnica da assistência farmacêutica no Município de Xinguara, Pará.

\section{Município de Xinguara, Pará}

Xinguara é constituído pelo distrito sede, Vila Rio Vermelho e Vila São José. Localiza-se na zona fisiográfica do planalto na Mesorregião do Sudeste Paraense, estando a 781,7 km de distância da capital do Estado (Belém). Segundo estimativas do Instituto Brasileiro de Geografia e Estatística (IBGE) de 2015 a população estima-se a 42.188 de habitantes e na contemporaneidade está resguardada sob o código de município n 1508407 . Passou à condição de município por meio da Lei 
$\mathrm{n}^{\circ}$ 5.028, de 13 de maio de 1982, Xinguara, sendo desmembrado de Conceição do Araguaia e instalado em 31 de dezembro de 1983, passando à categoria de cidade. Em 1996, por meio da Lei n 5.961 , de 24 de abril, sofreu novo desmembramento de suas terras para dar origem ao município de Sapucaia, Pará (Pará, 2015; 2017).

A Secretaria Municipal de Saúde de Xinguara é um órgão da administração direta, tem como atribuições o planejamento, desenvolvimento, orientação, coordenação e execução das políticas gerais de saúde do município, o que compreende tanto o cuidado ambulatorial quanto hospitalar, bem como planejar, desenvolver e executar as ações de vigilância sanitária, vigilância em saúde e vigilância epidemiológicas afetadas a sua competência. Estrutura-se e a partir de: Secretário de Saúde, Secretário Adjunto de Saúde, Coordenação de Gestão da Atenção Básica, Coordenação de Média e Alta Complexidade Ambulatorial e Hospitalar, Coordenação de Vigilância em Saúde, Coordenação de Assistência Farmacêutica (Central de Abastecimento Farmacêutico - CAF), Coordenação de Educação e Saúde, Coordenação do Centro de Atenção Psicossocial (CAPS), Coordenação de Gestão Administrativa, Gestão de Contabilidade, Gestão de Finanças e Tesouraria, Gerência de Recursos Humanos, Unidade de Pronto Atendimento (UPA), Direção do Hospital Municipal.

Dentre as unidades ambulatoriais cadastradas no SIA-SUS, o município possui dez Unidades Básicas de Saúde, seis Ambulatórios Especializados, um Consultório Isolado, três Farmácias, Três Hospitais Gerais, uma Policlínica, quatro Unidades de Serviço de Apoio de Diagnóstico e Terapia e uma Unidade Móvel de nível Pré-hospitalar de Urgência/Emergência. Quando ao número de leitos dispõe de 152 leitos Hospitalares, 8 leitos em Ambulatórios e 1 leito de Urgência. O total é de 161 leitos, sendo que 60 pertencem à esfera municipal e 92 à rede privada conveniada. Xinguara dispõe de 3,76 leitos para cada mil habitantes (Pará, 2015; 2017).

A Coordenação Técnica de Assistência Farmacêutica (CTAF); de caráter técnico e político, está vinculada à Secretaria de Saúde do Município de Xinguara, Pará (SESMA/PMB). É composta por onze farmacêuticos, sendo 7 concursados e 4 contratados, dentre outros funcionários de nível médio. Desenvolve suas atividades articulada com dez Unidades Básicas de Saúde, seis Ambulatórios Especializados, um Consultório Isolado, três Farmácias, Três Hospitais Gerais, uma Policlínica, quatro Unidades de Serviço de Apoio de Diagnóstico e Terapia e uma Unidade Móvel de nível Pré-hospitalar de Urgência/Emergência.

\section{Revisão Sistemática}

O primeiro passo foi fazer uma revisão sistemática. Sabe-se que a revisão sistemática é um método de síntese de evidências que avalia criticamente e interpreta todas as pesquisas relevantes disponíveis para uma questão particular, área do conhecimento ou fenômeno de interesse. Por se tratar de método explícito e sistemático para identificar, selecionar e avaliar a qualidade de evidências, as revisões sistemáticas são tipos de estudos produzidos por uma metodologia confiável, rigorosa e auditável. Os métodos estatísticos - metanálises, normalmente são inseridos na análise e síntese dos resultados, permitindo aumentar a amostra e a precisão dos desfechos avaliados (Brasil, 2012; Haby et al., 2016).

\section{Planejamento estratégico situacional}

O segundo passo foi realizar o Planejamento Estratégico Situacional (PES), um processo que permite a identificação, priorização e explicação de problemas, a definição de objetivos, a elaboração de operações e ações para alcançar os objetivos, a análise estratégica da viabilidade e, a construção de indicadores para a avaliação da implantação do Plano Operativo, acontecendo em quatro momentos didáticos: explicativo, normativo, estratégico e tático-operacional (Freitas, 2015; Darosi, 2015).

O Planejamento Estratégico Situacional (PES) possibilita situar os problemas em um contexto amplo, mantendo a riqueza da análise de viabilidades e de possibilidades de intervenção na realidade, em vários cenários (Freitas, 2015; Darosi, 
2015). Sabe-se que o uso de ferramentas de planejamento permite o melhor aproveitamento do tempo e dos recursos, aumentando a possibilidade de atingir objetivos determinados. $\mathrm{O}$ alcance de objetivos complexos pode ser facilitado quando o planejamento é realizado com a participação social, de forma interdisciplinar, intrasetorial e intersetorial (Matus, 1993; OMS, 2014).

Participaram da "Oficina de Planejamento Estratégico Situacional da Assistência Farmacêutica do Município de Xinguara, Pará" as seguintes instituições: Gabinete da Secretaria Municipal de Saúde, Técnicos da Coordenação de Gestão da Atenção Básica, Técnicos da Coordenação da Vigilância em Saúde, Técnicos da Coordenação de Gestão de Finanças e Tesouraria, Técnicos da Coordenação da Unidade de Pronto Atendimento (UPA), Técnicos da Coordenação do Hospital Municipal.

\section{Diagnóstico Situacional da Assistência Farmacêutica}

O terceiro passo foi investigar o processo de governança e da gestão técnica da assistência farmacêutica, entrevistando a secretária municipal de saúde, o coordenador técnico da assistência farmacêutica e técnicos de nível superior diretamente ligados a logística da assistência farmacêutica no município de Xinguara, Pará. Utilizou-se de quatro modelos de formulários estruturados; sendo os resultados apresentados nos Quadro 1 (Componentes e Práticas de Governança) (Gomes, 2009; Brasil, 2013), Quadro 2 (Indicadores para a gestão técnica da assistência farmacêutica) (Brasil, 2011; 2012; 2013; 2017a; Leite; Mendes \& Campese, 2015; Soler et al., 2018), Quadro 3 (Logística da assistência farmacêutica) (Pará, 2018; Leite; Mendes \& Campese, 2015) e Quadro 4 (Planejamento e gestão em saúde e da assistência farmacêutica) (Brasil, 2017b; Pará, 2018; Soler et al., 2018). As respostas foram consensuadas pelos entrevistados. Os resultados estão apresentados na forma dicotômica de "sim" e "não", utilizando-se da síntese narrativa quanto ao cumprimento ou não das práticas inerentes aos instrumentos de planejamento, gestão e governança, monitoramento e avaliação da assistência farmacêutica.

Esta pesquisa-ação foi registrada na Plataforma Brasil (SISNEP) sob CAAE nº 89599518.0.0000.0018 e Parecer Consubstanciado ${ }^{\circ}$ 2.911.716, aprovada conforme os termos da Resolução do CNS n 466 de 12 de dezembro de 2012 e da Resolução nº 510, de 07 de abril de 2016 (Brasil, 2021; 2016).

\section{Resultados e Discussão}

Apresenta-se evidências sobre tipos de intervenções relacionadas a qualidade da assistência farmacêutica, os desfechos da oficina de planejamento estratégico situacional, o cumprimento de indicadores relacionados as políticas setoriais, práticas de planejamento, gestão e governança relacionadas a assistência farmacêutica em Xinguara, Pará.

\section{Evidências de intervenções que asseguram uma melhor qualidade da assistência farmacêutica}

A revisão sistemática permitiu achados de distintos tipos de intervenções que asseguram uma melhor qualidade da assistência farmacêutica em nível municipal; tais como, medidas educativas, capacitação profissional e de intervenções organizacionais que fortalecem a gestão técnica da assistência farmacêutica em nível municipal; ou seja:

- Almeida et al., (2018); Medeiros, (2018); Meneses et al., (2018); Lourenço et al., (2018); Torres et al., (2014), apresentam evidências de que intervenções educacionais para profissionais da saúde proporcionam melhorias significativas na logística da assistência farmacêutica.

- Soler \& Maia (2019); Almeida et al., (2018); Maschietto, (2018); Medeiros, (2018); Meneses et al., (2018); Chiaroti et al., (2017); Oliveira et al., (2017); Scalercio, (2017); Torres et al., (2014), apresentam evidências de que a prestação de serviços farmacêuticos (cuidado farmacêutico) aos usuários qualificam a assistência farmacêutica no município. 
- Almeida et al., (2018); Scalercio, (2017); Soler et al., (2017), apresentam evidências de que a contratação de Profissionais Farmacêuticos são determinantes para a melhoria da assistência farmacêutica e para o acesso aos medicamentos.

- Almeida et al., (2018); Martins, (2018); Lourenço et al., (2018); Meneses et al., (2018); Oliveira et al., (2017); Medeiros, (2018); Scalercio, (2017); Chiaroti et al., (2017); Soler et al., (2017), Torres et al., (2014); Jaberidoost et al., (2013); Merisio et al., (2012); Amaral, (2011), apresentam evidências de que intervenções organizacionais fortalecem a gestão técnica da assistência farmacêutica, reduzindo custos e melhorando o acesso aos medicamentos.

\section{Planejamento estratégico situacional}

A "Oficina de Planejamento Estratégico Situacional da Assistência Farmacêutica do Município de Xinguara, Pará" foi realizada nos dias 26 e 27 de março de 2019, totalizando 12 horas de trabalho. Participaram da oficina: 2 farmacêuticos do hospital municipal, 2 farmacêuticos da unidade de pronto atendimento (UPA), 1 farmacêutico da vigilância sanitária, 2 farmacêuticos farmácia municipal, 1 representante do setor de compras, 1 farmacêutico coordenador da assistência farmacêutica municipal, 1 farmacêutico coordenador da central de abastecimento farmacêutico e 1 enfermeiro coordenador da atenção básica.

Partiu-se de indicadores de estrutura, de processos e de resultados relacionados a assistência farmacêutica, visando identificar potenciais problemas e seus respectivos descritores, a partir do qual se fez a matriz de priorização, em que cada participante emitiu a pontuação para os problemas descritos na matriz. Após a somatória das pontuações atribuídas para cada problema, elegeu-se como principal problema a "Falta de padronização de medicamentos no município" (Tabela 1).

Tabela 1 - Problemas identificados e seus desfechos.

\begin{tabular}{|c|c|c|c|}
\hline $\mathbf{N}^{\circ}$ & PROBLEMA IDENTIFICADO & $\begin{array}{l}\text { SITUAÇÃO EM } \\
\text { JUNHO DE } 2019 \\
\end{array}$ & $\begin{array}{l}\text { SITUAÇÃO EM } \\
\text { MARÇO DE } 2021 \\
\end{array}$ \\
\hline 01 & $\begin{array}{l}\text { Falta de planejamento, organização e articulação de ações/atividades/tarefas na } \\
\text { Assistência Farmacêutica. }\end{array}$ & Pactuado & Pactuado \\
\hline 02 & $\begin{array}{l}\text { Falta de dados sobre cobertura e aceitação: gasto mensal com medicamentos as } \\
\text { unidades solicitantes /medicamentos genéricos adquiridos. }\end{array}$ & Correção em curso & Correção em curso \\
\hline 03 & $\begin{array}{l}\text { Falta de dados sobre eficiência do serviço: perdas de medicamentos, demanda } \\
\text { atendida x demanda não atendida. }\end{array}$ & Correção em curso & Correção em curso \\
\hline 04 & Obstáculos na comunicação interna dentro da Secretária de Saúde. & Pactuado & Pactuado \\
\hline 05 & Falta de Farmacêutico no CAPS. & Resolvido & Resolvido \\
\hline 06 & $\begin{array}{l}\text { Ausência de POP na Central de Abastecimento Farmacêutico para Boas práticas } \\
\text { de assistência farmacêutica. }\end{array}$ & Correção em curso & Resolvido \\
\hline 07 & Falta de programação e aquisição de medicamento de acordo com a demanda. & Correção em curso & Resolvido \\
\hline 08 & $\begin{array}{l}\text { Falta de Infraestrutura na Central de Abastecimento Farmacêutico: forro, } \\
\text { iluminação, refrigeração e pintura. }\end{array}$ & Resolvido & Resolvido \\
\hline 09 & Falta da padronização de Medicamentos. & Correção em curso & Resolvido \\
\hline 10 & Ausência de reuniões técnicas entre os farmacêuticos. & Pactuado & Pactuado \\
\hline 11 & Desabastecimento de medicamentos, insumos e materiais hospitalares. & Correção em curso & Resolvido \\
\hline 12 & Falta de comunicação com os setores envolvidos com a assistência farmacêutica. & Pactuado & Pactuado \\
\hline 13 & $\begin{array}{l}\text { Falta de capacitação profissional para o desenvolvimento da assistência } \\
\text { farmacêutica. }\end{array}$ & Pactuado & Pactuado \\
\hline 15 & Falta de farmacêutico para o processo licitatório. & Pactuado & Correção em curso \\
\hline 16 & $\begin{array}{l}\text { Comprometimento do estoque planejado para atender demanda judiciais e ações } \\
\text { não planejadas. }\end{array}$ & Correção em curso & Resolvido \\
\hline 17 & Sistema HORÚS com funcionamento irregular. & Pactuado & Resolvido \\
\hline 18 & Aprimorar o comprometimento da coordenação da assistência farmacêutica. & Pactuado & Resolvido \\
\hline 19 & Ausência de uma Comissão de Farmácia e Terapêutica. & Resolvido & Resolvido \\
\hline 20 & Ausência de estruturação física da Farmácia Municipal. & Correção em curso & Correção em curso \\
\hline 21 & Organização e registro dos serviços prestados pela CAF aos pacientes. & Resolvido & Resolvido \\
\hline
\end{tabular}

Fonte: Trabalho de campo - Planejamento Estratégico Situacional e o fortalecimento da Central de Abastecimento Farmacêutico do município de Xinguara, Pará. 
Para o problema pactuado foi elaborado o diagrama de causa e efeito (espinha de peixe), que embasado nos descritores, permitiu definir a imagem-objetivo; ou seja, "Relação de Medicamentos Essenciais da Secretaria de Saúde do Município de Xinguara, Pará".

A matriz do momento normativo foi desenvolvida a partir da causa convergente "Ausência de planejamento estratégico situacional direcionado a assistência farmacêutica" e da consequência convergente "Agravamento dos problemas de saúde dos usuários do Sistema Único de Saúde no município de Xinguara, Pará", o que possibilitou definir como objetivo geral: "Elaborar a Relação Municipal de Medicamentos Essenciais para Xinguara, Pará"; proporcionando a melhoria do acesso, da qualidade dos medicamentos e da redução de recursos financeiros. A partir das causas e consequências secundárias foram definidos os objetivos específicos, para os quais foram estabelecidas as operações e ações, conforme preconizado pela matriz do momento normativo.

Foram, também, estabelecidas as demais operações e ações do plano operativo e o plano estratégico situacional para "Elaborar a Relação Municipal de Medicamentos Essenciais para Xinguara, Pará". A próxima etapa foi analisar a viabilidade e factibilidade por meio da matriz do momento estratégico.

O momento estratégico foi um diferencial do Planejamento Estratégico Situacional (PES), pois trouxe à reflexão as situações descritas no momento normativo (o que deve ser), mas, que por algum motivo não estavam em condições de serem executadas, sendo representadas como déficit. Construiu-se mecanismos para viabilizar as ações e operações essenciais para que o plano operativo se tornasse exequível.

Para cada objetivo específico foi feita a análise estratégica referente ao problema "Ausência de planejamento estratégico situacional direcionado a assistência farmacêutica" em busca da imagem-objetivo: "Relação Municipal de Medicamentos Essenciais para Xinguara, Pará"; obtendo-se, assim a matriz do momento estratégico.

Para finalizar o plano operativo, estabeleceu-se, por meio do protocolo, os indicadores de avaliação e os indicadores de monitoramento para o acompanhamento de sua execução. Com os indicadores pactuados foi possível a elaboração da matriz final do plano operativo com a inclusão das operações e ações estratégicas.

O Planejamento Estratégico Situacional (PES) se mostrou adequado ao ampliar o conhecimento e a capacidade de gestão dos atores participantes. Também se apresenta com potencial para contribuir para a reorganização dos serviços de saúde e da Assistência Farmacêutica em nível local. Promoveu ganhos significativos para a assistência farmacêutica no município de Xinguara, Pará; sendo que, a partir dos desfechos alcançados se tem conhecimento da amplitude de trabalhos que ainda precisam ser feitos.

Importante registrar os produtos elaborados a partir da "Oficina de Planejamento Estratégico Situacional da Assistência Farmacêutica do Município de Xinguara, Pará" e depositados no Portal EduCapes:

- Lista de Medicamentos Essenciais Disponibilizados pelo Sistema Único de Saúde em Xinguara, Pará (http://educapes.capes.gov.br/handle/capes/567705).

- Formulário Terapêutico Municipal de Xinguara, Pará: 2019 (http://educapes.capes.gov.br/handle/capes/567706)

- Procedimento Operacional Padrão: Manual de Boas Práticas da Central de Abastecimento Farmacêutico no Município de Xinguara, Pará (http://educapes.capes.gov.br/handle/capes/567723).

Alcançou-se ganhos significativos para a assistência farmacêutica no município de Xinguara, Pará; sendo que, a partir dos desfechos alcançados se tem conhecimento da amplitude de trabalhos que ainda precisam ser feitos. 


\section{Cumprimento de indicadores relacionados as práticas de governança}

Os resultados das práticas de governança no nível da coordenação técnica de assistência farmacêutica quanto as pessoas e competências, princípios e comportamentos, liderança organizacional, relacionamento com partes interessadas, estratégia organizacional, alinhamento transorganizacional, estrutura de governança, gestão de riscos e controle interno, auditoria interna e accountability e transparência estão apresentados no Quadro 1.

Quadro 1 - Práticas de governança no nível da coordenação técnica de assistência farmacêutica (Continua)

\begin{tabular}{|c|c|c|}
\hline Práticas quanto a Pessoas e competências & Sim & Não \\
\hline $\begin{array}{l}\text { Prática L1.1 Utiliza processo transparente e formalizado que oriente a indicação, a seleção e a nomeação de membros da } \\
\text { alta administração e da gestão operacional. }\end{array}$ & & $\mathrm{X}$ \\
\hline $\begin{array}{l}\text { Prática L1.2 Assegura a adequada capacitação dos membros da alta administração e da gestão operacional, de modo que } \\
\text { as competências necessárias à execução de suas atividades sejam desenvolvidas. O processo de capacitação deve ser } \\
\text { realizado quando esses forem nomeados para novas funções ou quando se fizer necessário. }\end{array}$ & $\mathrm{X}$ & \\
\hline Prática L1.3 Estabelece sistema de avaliação de desempenho dos membros da alta administração e da gestão operacional. & & $\mathrm{X}$ \\
\hline $\begin{array}{l}\text { Prática L1.4 Garanti que o conjunto dos benefícios da alta administração seja transparente e adequado para atrair bons } \\
\text { profissionais e estimulá-los a se manterem focados nos resultados organizacionais. }\end{array}$ & $\mathrm{X}$ & \\
\hline Práticas quanto aos Princípios e comportamentos & Sim & Não \\
\hline $\begin{array}{l}\text { Prática L2.1 Adota código de ética e conduta formalmente instituído e suficientemente detalhado e claro que defina } \\
\text { padrões de comportamento aplicáveis aos membros dos conselhos, aos da alta administração e aos gerentes da } \\
\text { organização. }\end{array}$ & $\mathrm{X}$ & \\
\hline $\begin{array}{l}\text { Prática L2.2 Estabelece mecanismos de controle adequados para evitar que preconceitos, vieses ou conflitos de interesse } \\
\text { influenciem as decisões e as ações de membros dos conselhos, da alta administração e de gerentes. }\end{array}$ & $\mathrm{X}$ & \\
\hline $\begin{array}{l}\text { Prática L2.3 Age de acordo com padrões de comportamento, baseados nos valores e princípios constitucionais, legais e } \\
\text { institucionais e no código de ética e conduta adotado, servindo de exemplo para todos. }\end{array}$ & $\mathrm{X}$ & \\
\hline $\begin{array}{l}\text { Prática L2.4 Contribui para a boa reputação da organização por meio de boas relações com o cidadão e com outras } \\
\text { instituições. }\end{array}$ & $\mathrm{X}$ & \\
\hline Práticas quanto à liderança organizacional & Sim & Não \\
\hline $\begin{array}{l}\text { Prática L3.1 Avalia, direciona e monitora a gestão da organização, especialmente o alcance de metas institucionais e o } \\
\text { comportamento dos membros da alta administração e dos gerentes. }\end{array}$ & & $\mathrm{X}$ \\
\hline $\begin{array}{l}\text { Prática L3.2 Define os papéis e distribuir as responsabilidades entre os membros dos conselhos, da alta administração e os } \\
\text { gerentes, de modo a garantir o balanceamento de poder e a segregação de funções críticas. }\end{array}$ & & $\mathrm{X}$ \\
\hline $\begin{array}{l}\text { Prática L3.3 Responsabiliza-se, perante as estruturas de governança (internas e externas), pelo estabelecimento de } \\
\text { políticas e diretrizes para a gestão da organização e pelo alcance dos resultados previstos. }\end{array}$ & & $\mathrm{X}$ \\
\hline $\begin{array}{l}\text { Prática L3.4 Avalia os resultados das atividades de controle e dos trabalhos de auditoria e garantir que sejam adotadas as } \\
\text { providências cabíveis. }\end{array}$ & & $\mathrm{X}$ \\
\hline Práticas quanto ao Relacionamento com partes interessadas & Sim & Não \\
\hline $\begin{array}{l}\text { Prática E1.1 Estabelece modelo de participação social, no qual se promova o envolvimento da sociedade, dos usuários e } \\
\text { demais partes interessadas na definição de prioridades. }\end{array}$ & & $\mathrm{X}$ \\
\hline $\begin{array}{l}\text { Prática E1.2 Estabelece e divulgar canais de comunicação e consulta com as diferentes partes interessadas e assegurar sua } \\
\text { efetividade, consideradas as características e possibilidades de acesso de cada público-alvo. }\end{array}$ & & $\mathrm{X}$ \\
\hline $\begin{array}{l}\text { Prática E1.3 Publica, para conhecimento de todas as partes interessadas, a estrutura de governança vigente na organização, } \\
\text { assim como os papéis e as responsabilidades definidos. }\end{array}$ & & $\mathrm{X}$ \\
\hline Prática E1.4 Estabelece relação objetiva e profissional com a mídia, com outras instituições e com auditores. & $\mathrm{X}$ & \\
\hline $\begin{array}{l}\text { Prática E1.5 Assegura que decisões, estratégias, planos, ações, serviços e produtos fornecidos pela organização atendam } \\
\text { ao maior número possível de partes interessadas, de modo balanceado, equitativo, sem permitir a predominância dos } \\
\text { interesses de pessoas ou grupos. }\end{array}$ & $\mathrm{X}$ & \\
\hline Práticas quanto a Estratégia organizacional & Sim & Não \\
\hline $\begin{array}{l}\text { Prática E2.1 Estabelece modelo de gestão da estratégia que considere aspectos como transparência, comprometimento das } \\
\text { partes interessadas e foco em resultados. }\end{array}$ & $\mathrm{X}$ & \\
\hline $\begin{array}{l}\text { Prática E2.2 Estabelece modelo de gestão que favoreça o alinhamento de operações à estratégia e possibilite aferir o } \\
\text { alcance de benefícios, resultados, objetivos e metas. }\end{array}$ & $x$ & \\
\hline Prática E2.3 Estabelece a estratégia da organização e formalizá-la. & & $\mathrm{X}$ \\
\hline Prática E2.4 Comunica às partes interessadas a estratégia da organização. & $\mathrm{X}$ & \\
\hline $\begin{array}{l}\text { Prática E2.5 Monitora e avalia a execução da estratégia, os principais indicadores operacionais e os resultados da } \\
\text { organização. }\end{array}$ & $\mathrm{X}$ & \\
\hline Práticas quanto ao Alinhamento transorganizacional & Sim & Não \\
\hline $\begin{array}{l}\text { Prática E3.1 Estabelece mecanismos de articulação, comunicação e colaboração que permitam alinhar estratégias e } \\
\text { operações das organizações envolvidas em políticas transversais e descentralizadas. }\end{array}$ & & $X$ \\
\hline $\begin{array}{l}\text { Prática E3.2 Estabelece, de comum acordo, objetivos coerentes e alinhados entre todas as organizações envolvidas na } \\
\text { implementação da estratégia, para que os resultados esperados possam ser alcançados. }\end{array}$ & & $X$ \\
\hline
\end{tabular}




\begin{tabular}{|c|c|c|}
\hline Práticas quanto a Estrutura de governança & Sim & Não \\
\hline $\begin{array}{l}\text { Prática E4.1 Estabelece e manter política de delegação e de reserva de poderes, de forma a assegurar a capacidade de } \\
\text { avaliar, dirigir e monitorar a organização. }\end{array}$ & & $X$ \\
\hline $\begin{array}{l}\text { Prática E4.2 Define os papéis e distribuir as responsabilidades entre os conselhos, a alta administração e a gestão } \\
\text { operacional, de modo a garantir o balanceamento de poder e a segregação de funções críticas. }\end{array}$ & & $\mathrm{X}$ \\
\hline $\begin{array}{l}\text { Prática E4.3 Define, de forma clara, procedimentos e regulamentos afetos a gestão da estrutura interna de governança, } \\
\text { bem como os seguintes processos: elaboração, implementação e revisão de políticas; tomada de decisão, monitoramento e } \\
\text { controle. }\end{array}$ & & $\mathrm{X}$ \\
\hline $\begin{array}{l}\text { Prática E4.4 Define instâncias internas de apoio à governança e indicar como elas se relacionam com as demais estruturas } \\
\text { de governança. }\end{array}$ & & $X$ \\
\hline Práticas quanto a Gestão de riscos e controle interno & Sim & Não \\
\hline $\begin{array}{l}\text { Prática C1.1 Fomenta a cultura de gestão de riscos como fator essencial para implementar a estratégia, tomar decisões e } \\
\text { realizar os objetivos da organização. }\end{array}$ & & $X$ \\
\hline Prática C1.2 Estabelece política e estrutura integrada de gestão de riscos e controle interno. & & $\mathrm{X}$ \\
\hline Prática C1.3 Assegura que a gestão de riscos e o controle interno sejam parte integrante dos processos organizacionais. & & $\mathrm{X}$ \\
\hline $\begin{array}{l}\text { Prática C1.4 Considera os riscos que têm impacto sobre outras organizações públicas e demais partes interessadas e } \\
\text { comunicar, consultar e compartilhar informações regularmente com essas partes. }\end{array}$ & & $\mathrm{X}$ \\
\hline $\begin{array}{l}\text { Prática C1.5 Monitora e analisa a gestão de riscos e o sistema de controle interno, a fim de assegurar que sejam eficazes e } \\
\text { apoiem o desempenho organizacional. }\end{array}$ & & $\mathrm{X}$ \\
\hline Práticas quanto a Auditoria interna & Sim & Não \\
\hline Prática C2.1 Estabelece estatuto que defina o propósito, a autoridade e a responsabilidade da auditoria interna. & & $\mathrm{X}$ \\
\hline $\begin{array}{l}\text { Prática C2.2 Prove condições para que a auditoria interna seja independente e para que os auditores internos sejam } \\
\text { proficientes, atuem de forma objetiva e com zelo profissional ao executar seus trabalhos. }\end{array}$ & & $X$ \\
\hline $\begin{array}{l}\text { Prática C2.3 Garante que seja desenvolvido e mantido um programa de garantia de qualidade e melhoria da auditoria } \\
\text { interna, compreendendo todos os aspectos da atividade. }\end{array}$ & & $\mathrm{X}$ \\
\hline Prática C2.4 Assegura que a auditoria interna adicione valor à organização. & & $\mathrm{X}$ \\
\hline Práticas quanto ao Accountability e transparência & Sim & Não \\
\hline $\begin{array}{l}\text { Prática C3.1 Publica relatórios periódicos de desempenho dos sistemas de governança e de gestão, de acordo com a } \\
\text { legislação vigente e com os princípios de accountability. }\end{array}$ & & $X$ \\
\hline $\begin{array}{l}\text { Prática C3.2 Publica, juntamente com os relatórios periódicos, parecer da auditoria interna quanto à confiabilidade das } \\
\text { informações prestadas, a regularidade das operações subjacentes e o desempenho das operações. }\end{array}$ & & $\mathrm{X}$ \\
\hline Prática C3.3 Publica a decisão quanto à regularidade das contas proferida pelo órgão de controle externo. & & $\mathrm{X}$ \\
\hline $\begin{array}{l}\text { Prática C } 3.4 \text { Publica eventuais avaliações da adequação e do desempenho dos sistemas de governança e de gestão } \\
\text { realizadas pelos órgãos de controle externo. }\end{array}$ & & $X$ \\
\hline $\begin{array}{l}\text { Prática C3.5 Avalia, periodicamente, o grau de satisfação das partes interessadas com as estratégias e ações da } \\
\text { organização, a satisfação quanto a serviços e produtos fornecidos, assim como avaliar a imagem, a reputação e a } \\
\text { confiança do público na organização. }\end{array}$ & & $\mathrm{X}$ \\
\hline $\begin{array}{l}\text { Prática C3.6 Compromete-se com a transparência da organização às partes interessadas, admitindo-se o sigilo, como } \\
\text { exceção, nos termos da lei. }\end{array}$ & & $\mathrm{X}$ \\
\hline $\begin{array}{l}\text { Prática C3.7 De ofício, garante que sejam apurados os fatos com indício de irregularidade ou contrários à política de } \\
\text { governança, promovendo a responsabilização em caso de comprovação. }\end{array}$ & & $\mathrm{X}$ \\
\hline
\end{tabular}

Fonte: Trabalho de campo - Planejamento Estratégico Situacional e o fortalecimento da Central de Abastecimento Farmacêutico do município de Xinguara, Pará.

Os achados permitem reflexionar sobre o funcionamento da Coordenação Técnica de Assistência Farmacêutica (CTAF) para com a sociedade, como instrumento necessário para o funcionamento da assistência farmacêutica de forma eficiente. Sabe-se que os resultados de uma organização dependem dos Recursos Humanos que nela trabalham; os quais, devem possuir competências apropriadas. Os valores éticos são princípios que não se limitam apenas as normas, costumes e traduções culturais de uma sociedade; mas, também, precisam estar focados nos aspectos compreendidos como essenciais para o melhor modo de viver ou agir em sociedade (Brasil, 2013; Freitas, 2015; Soler et al., 2018; Maschietto, 2018). Ainda há muito em que avançar.

Constatou-se que a Coordenação Técnica de Assistência Farmacêutica (CTAF) está submetida a uma complexa estrutura hierárquica, sendo que cada farmacêutico tem autonomia em seu setor de trabalho e lidera conforme sua experiência profissional. A CTAF não participa diretamente dos processos de planejamento de saúde; ou seja, ausente enquanto liderança organizacional. 
A Coordenação Técnica de Assistência Farmacêutica (CTAF) se relaciona diretamente com as 12 unidades municipais de saúde (UMS), 1 centro de especialidade (CE), 1 unidade de pronto atendimento (UPA), 1 hospital municipal (HM) e 1 Farmácia Municipal. Quanto ao relacionamento com partes interessadas foram observadas uma relação indireta com Departamento de administração (DEAD), Departamento de ações em saúde (DEAS), Departamento de vigilância sanitária (DEVISA), Departamento de regulação (DERE), Departamento de vigilância à saúde (DEVS) e com o Gabinete do Secretário de saúde (GSS). Entretanto, a CTAF não apresenta autonomia, ficando na responsabilidade de cada técnico farmacêutico estabelecer suas estratégias conforme as análises de seus setores de trabalho, desdobrá-las em plano de ação e acompanhar sua implementação, oferecendo os meios necessários ao alcance dos objetivos institucionais e a maximização dos resultados.

A assistência farmacêutica é uma política de natureza transversal, sendo essencial que haja mecanismos institucionalizados de coordenação, de forma a criar condições para a atuação conjunta e sinérgica, evitando ainda superposições ou esforço mutuamente contraproducentes. Enfim, no que se refere as práticas de governança há muito o que ser aprimorado; em especial, aquelas relacionadas a gestão de risco, auditoria interna e accountability e transparência (Brasil, 2013; Freitas, 2015; Soler et al., 2018; Maschietto, 2018).

\section{Cumprimento de indicadores relacionados Instrumentos de Planejamento e Gestão, Gestão Técnica da Assistência farmacêutica, Gestão clínica do medicamento e Políticas Setoriais}

O Planejamento é um recurso imprescindível e indispensável para conferir qualidade técnica e políticas as diferentes áreas de intervenção profissional. Na realidade este recurso é cada vez mais requisitado pelas diversas instituições e grupos como alternativa capaz de pensar e concretizar ações sustentadas por valores éticos de defesa da liberdade e da pluralidade humana, visando a equidade da participação social (Freitas, 2018). Como já mencionado, o planejamento em saúde deve estar pautado em três dispositivos legais: o Decreto $n^{\circ}$ 7.508, de junho de 2011 (Brasil, 2011), a Lei Complementar ${ }^{\circ} 141$, de 13 de janeiro de 2012 (Brasil, 2012), e a Portaria n ${ }^{\circ}$ 2.135, 25 de setembro de 2013 (Brasil, 2013). Estes dispositivos regulamentam diretrizes para o planejamento do SUS, estabelecendo como instrumentos do planejamento em saúde o Plano Municipal de Saúde (PMS), a Programação Anual da Saúde (PAS) e o Relatório Anual de Gestão (RAG); os quais orientam os demais pressupostos para o planejamento em saúde.

No Quadro 2 (cumprimento de indicadores relacionados instrumentos de planejamento e gestão, gestão técnica da assistência farmacêutica, gestão clínica do medicamento e políticas setoriais) se observa que os principais instrumentos de planejamento e gestão do Sistema Único de Saúde (SUS), vem sendo executados pela Secretária Municipal de Saúde de Xinguara, Pará.

Os achados revelam que embora tenha sido utilizados instrumentos de gestão; tais como, o Plano Anual de Saúde (PAS) e o Planejamento Plurianual (PPA), observa-se que na realidade a Assistência Farmacêutica precisa ser melhor trabalhada a partir desses instrumentos; ou seja, falta um planejamento que foque a melhoria do acesso aos medicamentos essenciais e seu uso racional em todos os serviços de saúde. Neste sentido, Maschietto (2018) e Medeiros (2018), chama a atenção da necessidade dos gestores em assegurar projetos e ações que aprimorem e facilitem o delineamento da gestão técnica da assistência farmacêutica. Importante destacar que Programação Geral das Ações e dos Serviços de Saúde (PGASS), coloca-se como instrumento de fortalecimento da governança regional, na medida em que se propõe a sistematizar os pactos entre os gestores das três esferas de governo, privilegiando este espaço como locus de negociação e estruturação da rede de atenção à saúde, integrando os serviços e os recursos disponíveis (Brasil, 2011; 2013).

No campo do planejamento e gestão em saúde, a Secretaria de Saúde de Xinguara, Pará, faz o Planejamento Municipal de Saúde (PMS), o Planejamento Anual de Saúde (PAS), o Relatório Anual de Gestão (RAG), o Relatório Detalhado do Quadrimestre Anterior (RDQA) e a Programação Geral das Ações e dos Serviços de Saúde (PGASS). Entretanto, estes 
instrumentos são elaborados por uma enfermeira, utilizando-se do DigiSUS; uma ferramenta do Ministério da Saúde para incorporação da saúde digital. Após construído é apresentado e pactuado no Conselho Municipal de Saúde (CMS), sendo em seguida apresentado em audiência pública para aprovação. Soler (2018), Maschietto (2018), Medeiros (2018) e Menezes e colaboradores (2018) registram evidências de que o aprimoramento da prática de governança e de uma gestão funcional e integrada são efetivas para melhorar a eficiência da Gestão Técnica da Assistência Farmacêutica. Há que se assegurar que o planejamento, o monitoramento e a avaliação das ações, atividades e tarefas inerentes à Assistência Farmacêutica ocorra de fato e de direito pelos seus pares.

Importante relatar que a Central de Abastecimento Farmacêutico (CAF) do município de Xinguara, Pará, possui um amplo espaço físico; entretanto, há problemas estruturais que dificultam o processo de armazenamento de medicamentos e insumos de forma adequada. Possui uma sala da administração com um banheiro anexo e mais duas salas grandes destinadas ao recebimento e armazenamento dos medicamentos. Há prateleiras e palletes em quantidades insuficiente para a organização dos medicamentos longe do contato do solo e paredes, apenas uma sala possui central de ar quantidade essa insuficiente que pode levar ao comprometimento da estabilidade físico-química dos medicamentos, o forro de gesso do teto de uma sala encontra-se deteriorado e o outro anexo não possui, a pintura encontra-se velha e com mofo, foi observado também iluminação insuficiente, comprometimento das instalações elétricas, ausência de extintores e equipamento eletrônico como computador em quantidade insuficiente. 
Quadro 2 - Cumprimento de indicadores relacionados instrumentos de planejamento e gestão, gestão técnica da assistência farmacêutica, gestão clínica do medicamento e políticas setoriais em Xinguara, Pará.

\begin{tabular}{|c|c|c|c|}
\hline \multicolumn{2}{|c|}{$\begin{array}{ll}\text { CRITÉRIOS* }^{*} & \\
\end{array}$} & PRESENTE & AUSENTE \\
\hline \multicolumn{4}{|c|}{ Instrumentos de Planejamento e Gestão } \\
\hline \multicolumn{2}{|c|}{ Plano Municipal de Saúde (PMS) } & $\mathrm{X}$ & \\
\hline \multicolumn{2}{|c|}{ Programação Anual de Saúde (PAS) } & $\mathrm{X}$ & \\
\hline \multicolumn{2}{|c|}{ Plano Diretor de Regionalização (PDR) } & $\mathrm{X}$ & \\
\hline \multicolumn{2}{|c|}{ Contrato Organizativo de Ação Pública (COAP) } & $\mathrm{X}$ & \\
\hline \multicolumn{2}{|c|}{ Programação Geral das Ações e dos Serviços de Saúde (PGASS) } & $\mathrm{X}$ & \\
\hline \multicolumn{2}{|c|}{ Lei de Diretrizes Orçamentária (LDO) } & $\mathrm{X}$ & \\
\hline \multicolumn{2}{|c|}{ Lei Orçamentária Anual (LOA) } & $\mathrm{X}$ & \\
\hline \multicolumn{2}{|c|}{ Plano Plurianual (PPA) } & $\mathrm{X}$ & \\
\hline \multicolumn{2}{|c|}{ Relatório Detalhado do Quadrimestre Anterior (RDQA) } & $\mathrm{X}$ & \\
\hline \multicolumn{2}{|c|}{ Relatório Anual de Gestão (RAG) } & $\mathrm{X}$ & \\
\hline \multicolumn{2}{|c|}{ Planejamento Regional Integrado (PRI) } & $\mathrm{X}$ & \\
\hline \multicolumn{4}{|c|}{ Gestão Técnica da Assistência farmacêutica } \\
\hline \multicolumn{2}{|c|}{ Componente Básico da Assistência Farmacêutica } & $\mathrm{X}$ & \\
\hline \multicolumn{2}{|c|}{ Componente Estratégico da Assistência Farmacêutica } & $\mathrm{X}$ & \\
\hline \multicolumn{2}{|c|}{ Componente Especializado da Assistência Farmacêutica } & $\mathrm{X}$ & \\
\hline \multicolumn{2}{|c|}{ Demandas Judiciais na Assistência Farmacêutica } & $\mathrm{X}$ & \\
\hline \multicolumn{2}{|c|}{ Seleção e Programação de Medicamentos } & $\mathrm{X}$ & \\
\hline \multicolumn{2}{|c|}{ Aquisição de Medicamentos } & $\mathrm{X}$ & \\
\hline \multicolumn{2}{|c|}{ Armazenamento de Medicamentos } & $\mathrm{X}$ & \\
\hline \multicolumn{2}{|c|}{ Dispensação de Medicamentos } & $\mathrm{X}$ & \\
\hline \multicolumn{2}{|l|}{ Sistema Hórus } & $\mathrm{X}$ & \\
\hline \multirow{4}{*}{ Qualifar-SUS } & Eixo Estrutura & $\mathrm{X}$ & \\
\hline & Eixo Educação & $\mathrm{X}$ & \\
\hline & Eixo Informação & $X$ & \\
\hline & Eixo Cuidado & $\mathrm{X}$ & \\
\hline \multicolumn{4}{|c|}{ Gestão clínica do medicamento } \\
\hline \multicolumn{2}{|c|}{ Protocolos Clínicos e Diretrizes Terapêuticas } & & $\mathrm{X}$ \\
\hline \multicolumn{2}{|c|}{ Cuidado Farmacêutico } & & $\mathrm{X}$ \\
\hline \multicolumn{2}{|c|}{ Seguimento Farmacoterapêutico } & & $\mathrm{X}$ \\
\hline Educação em & & & $\mathrm{X}$ \\
\hline Orientações $\mathrm{Fr}$ & s para o Uso Racional de Medicamentos & & $\mathrm{X}$ \\
\hline Farmacovigilâ & & & $\mathrm{X}$ \\
\hline Serviço de Inf & ore Medicamentos (SIM) & & $\mathrm{X}$ \\
\hline Políticas Seto & & & \\
\hline $\begin{array}{l}\text { Política Nacio } \\
\text { Ministro da Sa }\end{array}$ & $\begin{array}{l}\text { cas Integrativas e Complementares no SUS - Portaria } n^{\circ} 971 \text {, do Gabinete do } \\
\text { de maio de } 2006 \text {. }\end{array}$ & & $\mathrm{X}$ \\
\hline Política Nacio & as Medicinais e Fitoterápicos -Decreto $\mathrm{n}^{\circ} .5 .813$, de 22 de junho de 2006. & & $\mathrm{X}$ \\
\hline $\begin{array}{l}\text { Portaria } \mathrm{n}^{\circ} 84 \mathrm{C} \\
\text { Musicoterapia } \\
\text { Comunitária Ir }\end{array}$ & $\begin{array}{l}\text { março de 2017: Arteterapia, Ayurveda, Biodança, Dança Circular, Meditação, } \\
\text { tia, Osteopatia, Quiropraxia, Reflexoterapia, Reiki, Shantala, Terapia } \\
\text { Yoga à Política Nacional de Práticas Integrativas e Complementares. }\end{array}$ & & $\mathrm{X}$ \\
\hline
\end{tabular}

*Adaptado de: Decreto $\mathrm{n}^{\mathrm{o}} 7.508$, de junho de $2011^{(7)}$, Lei Complementar $\mathrm{n}^{\circ} 141$, de 13 de janeiro de 2012(11) Portaria $\mathrm{n}^{\circ} 2.135,25$ de setembro de $2013^{(12)}$ e do Decreto $n^{\circ} 9.203$, de 22 de novembro de $2017^{(13)}$. Fonte: Trabalho de campo - Planejamento Estratégico Situacional e o fortalecimento da Central de Abastecimento Farmacêutico do município de Xinguara, Pará.

A Central de Abastecimento Farmacêutico (CAF) abastece com medicamentos e insumos semanalmente a Unidade de Pronto Atendimento (UPA), Hospital Municipal, Farmácia Municipal, Laboratório Municipal e a cada 15 dias é realizado o abastecimento das 8 unidades de saúde urbanas e 4 unidades de saúde na zona rural, de acordo com o farmacêutico coordenador, essa programação tem dado muito certo. É realizado o atendimento de pacientes, com tiras de glicemia, materiais para curativos extensos e fraldas geriátricas, porém os pacientes não são cadastrados e o serviço não é organizado. A logística da assistência farmacêutica é composta de uma série de processos que vão desde a seleção de medicamentos, programação, armazenamento, distribuição e a sua dispensação. Promover uma eficiente articulação dessa logística tem sido uma tarefa desafiadora (Santos et al., 2016). 
A Central de Abastecimento Farmacêutico (CAF) se utiliza do programa HORUS para a sua operacionalização, um sistema web disponibilizado pelo Ministério da Saúde, o qual não tem sido manuseado na sua integralidade devido à ausência e qualificação de recursos humanos; dificultando assim, a obtenção de dados quantitativos fidedignos para uma boa programação e aquisição de medicamentos e insumos, o que tem gerado a maior quantidade de uns itens e a falta de outros.

Registra-se que o município se cadastrou Qualifar-SUS no ano de 2018; mas, ainda não foi integralmente contemplado. Farmacêuticos participaram do Curso I de Gestão do Cuidado Farmacêutico na Atenção Básica (Eixo Educação), modalidade ensino a distância (EAD), realizado no período de fevereiro a junho de 2019.

\section{Cumprimento de indicadores relacionados a logística da assistência farmacêutica em Xinguara, Pará}

Os resultados apresentados no Quadro 3 (Cumprimento de indicadores relacionados a logística da assistência farmacêutica em Xinguara, Pará) demonstram que se cumprem os indicadores relacionados a seleção, programação, aquisição, armazenamento e distribuição de medicamentos. O ponto crítico está relacionado ao não cumprimento dos indicadores da dispensação de medicamentos; em especial, ao Cuidado Farmacêutico. Reconhece-se que a Logística da Assistência Farmacêutica é um dos fatores determinantes para a qualidade da prestação de serviços de saúde. Nesta direção, intervenções estratégicas que resultem na melhoria do acesso e do uso com qualidade de medicamentos são imprescindíveis (Santana, 2014; Almeida et al., 2018 \& Carvalho, 2017).

A dispensação de medicamentos é um fator preocupante. Observou-se a ausência de profissionais farmacêuticos em todas as Unidades Básicas de Saúde (UBS) do município de Xinguara, Pará. Carvalho (2017), relata que profissionais enfermeiros e médicos ficam descontentes com a ausência de farmacêuticos na equipe multiprofissional, reconhecendo que a presença do farmacêutico proporciona uma melhor gestão técnica da assistência farmacêutica com a gestão clínica do medicamento; ou seja, a melhoria do acesso e uso racional de medicamentos.

\section{Cumprimento de indicadores relacionados a gestão técnica da assistência farmacêutica no município de Xinguara, Pará}

O Quadro 4 (Cumprimento de indicadores relacionados a gestão técnica da assistência farmacêutica no município de Xinguara, Pará) demonstra que há muito o que melhor quanto aos indicadores de gestão técnica da assistência farmacêutica, cobertura e aceitação, eficiência, qualidade de medicamentos e de satisfação do usuário. A falta de pessoal qualificado se destaca com um problema a ser imediatamente resolvido. Menezes e colaboradores (2018) registram que uma gestão técnica da assistência farmacêutica evita conflitos e eleva o grau de satisfação de trabalhadores e usuários. Maschietto (2018) sinaliza a necessidade de alocação de investimento na assistência farmacêutica no requisito capacitação profissional, sendo muito importante para dispensação equânime e uso racional de medicamento. Medeiros (2018) relata que a qualificação do profissional farmacêutico e medidas educativas são necessárias para melhoria no processo de gestão do ciclo da assistência farmacêutica. 
Quadro 3 - Cumprimento de indicadores relacionados a logística da assistência farmacêutica em Xinguara, Pará.

\begin{tabular}{|c|c|c|}
\hline \multicolumn{3}{|l|}{ Logística Da Assistência Farmacêutica } \\
\hline & Presente & Ausente \\
\hline Seleção de medicamentos & $\mathrm{X}$ & \\
\hline Avaliação da utilização da Relação de Medicamentos na Rede & & $\mathrm{X}$ \\
\hline Comissão de Farmácia e Terapêutica institucionalizada & & $\mathrm{X}$ \\
\hline Comparação de custo/tratamento & $\mathrm{X}$ & \\
\hline Grau de conhecimento e utilização da Relação de Medicamentos & & $\mathrm{X}$ \\
\hline Grau de conhecimento e utilização de protocolos de tratamento & & $\mathrm{X}$ \\
\hline Grau de conhecimento e utilização do Memento Terapêutico & & $\mathrm{X}$ \\
\hline Critérios para inclusão e exclusão de medicamentos & & $\mathrm{X}$ \\
\hline Diagnostico do perfil epidemiológico & $\mathrm{X}$ & \\
\hline Memento Terapêutico / Protocolos Terapêuticos & & $\mathrm{X}$ \\
\hline Observação da disponibilidade dos medicamentos no mercado & $\mathrm{X}$ & \\
\hline Priorização de medicamentos com apresentação de melhor comodidade de uso para o paciente & $\mathrm{X}$ & \\
\hline Priorização de medicamentos com maior estabilidade e propriedade farmacocinética mais favorável & $\mathrm{X}$ & \\
\hline $\begin{array}{l}\text { Priorização de medicamentos considerados básicos e indispensáveis para atender a maioria dos problemas de } \\
\text { saúde da população }\end{array}$ & $X$ & \\
\hline Protocolos de tratamento & & $\mathrm{X}$ \\
\hline Relação de medicamentos nos serviços & & $\mathrm{X}$ \\
\hline Utilização de referências bibliográficas oficiais (idôneas) & & $\mathrm{X}$ \\
\hline \multicolumn{3}{|l|}{ Programação de medicamentos } \\
\hline Análise da capacidade instalada adequadamente & $\mathrm{X}$ & \\
\hline Análise da disponibilidade dos medicamentos no mercado & $\mathrm{X}$ & \\
\hline Análise do Consumo Histórico e demanda não-atendida & $\mathrm{X}$ & \\
\hline Análise dos estoques disponíveis & $\mathrm{X}$ & \\
\hline Análise dos preços de mercado & $\mathrm{X}$ & \\
\hline Análise e quantificação dos medicamentos de acordo com protocolo clínico & & $\mathrm{X}$ \\
\hline \multicolumn{3}{|l|}{ Aquisição de medicamentos } \\
\hline Cadastro de fornecedores & $\mathrm{X}$ & \\
\hline Catálogo de Compras & $\mathrm{X}$ & \\
\hline Identificação da disponibilidade dos recursos no atendimento à demanda & $\mathrm{X}$ & \\
\hline Normas e procedimentos administrativos de compra & & $\mathrm{X}$ \\
\hline Normas e procedimentos de recebimento de medicamentos & & $\mathrm{X}$ \\
\hline Registro e seleção de fornecedores & $\mathrm{X}$ & \\
\hline \multicolumn{3}{|l|}{ Armazenamento de medicamentos } \\
\hline Normas para instalações de armazenamento de medicamentos & $\mathrm{X}$ & \\
\hline Normas e procedimentos técnicos de armazenagem & & $\mathrm{X}$ \\
\hline Normas e manual de procedimentos técnicos & & $\mathrm{X}$ \\
\hline \multicolumn{3}{|l|}{ Distribuição de medicamentos } \\
\hline Calendário de entregas & $\mathrm{X}$ & \\
\hline Controle quantitativo e qualitativo & & $\mathrm{X}$ \\
\hline Meios de transporte e custos adequados & $\mathrm{X}$ & \\
\hline Normas de distribuição & $\mathrm{X}$ & \\
\hline \multicolumn{3}{|l|}{ Dispensação de medicamentos } \\
\hline Aconselhamento e seguimento ao paciente & & $\mathrm{X}$ \\
\hline Controle de qualidade físico do medicamento & & $\mathrm{X}$ \\
\hline Estudos de perfil farmacoterapêutico & & $\mathrm{X}$ \\
\hline Farmacovigilância & & $\mathrm{X}$ \\
\hline Normas e procedimentos de dispensação & & $\mathrm{X}$ \\
\hline Protocolo de atendimento ao paciente & & $\mathrm{X}$ \\
\hline
\end{tabular}

Fonte: Trabalho de campo - Planejamento Estratégico Situacional e o fortalecimento da Central de Abastecimento Farmacêutico do município de Xinguara, Pará. 
Quadro 4 - Cumprimento de indicadores relacionados a gestão técnica da assistência farmacêutica no município de Xinguara, Pará

\begin{tabular}{|c|c|c|}
\hline \multirow[b]{2}{*}{ INDICADORES } & \multicolumn{2}{|c|}{ Registro de informação } \\
\hline & Sim & Não \\
\hline \multicolumn{3}{|l|}{ Gestão Técnica da Assistência Farmacêutica } \\
\hline Ações de vigilância sanitárias programadas e executadas em relação aos medicamentos & $\mathrm{X}$ & \\
\hline Aplicação de recursos programados para assistência farmacêutica básica & $\mathrm{X}$ & \\
\hline Avaliação e acompanhamento das ações programadas & & $\mathrm{X}$ \\
\hline Dados e/ou indicadores sobre utilização racional de medicamentos & & $\mathrm{X}$ \\
\hline Demonstrativo físico-financeiro de aquisição por determinado período de tempo & $\mathrm{X}$ & \\
\hline Desempenho de fornecedores & & $\mathrm{X}$ \\
\hline Existência de pessoal capacitado para assistência farmacêutica & & $\mathrm{X}$ \\
\hline Número de dias entre a solicitação e aquisição de medicamentos & & $\mathrm{X}$ \\
\hline Recursos gastos com aquisição de medicamentos & $\mathrm{X}$ & \\
\hline \multicolumn{3}{|l|}{ Cobertura e Aceitação } \\
\hline \% de aceitação dos medicamentos da relação de medicamentos & & $\mathrm{X}$ \\
\hline$\%$ de gasto mensal com medicamentos para atender a atenção básica de saúde por unidade de serviço & & $\mathrm{X}$ \\
\hline$\%$ de medicamentos genéricos adquiridos & & $\mathrm{X}$ \\
\hline \% de prescrição de medicamentos não incluídos na Relação de Medicamentos & & $\mathrm{X}$ \\
\hline \% e/ou número de unidades atendidas mês/ano & $\mathrm{X}$ & \\
\hline Tempo médio gasto na reposição dos medicamentos nos serviços & $\mathrm{X}$ & \\
\hline \multicolumn{3}{|l|}{ Eficiência } \\
\hline$\%$ de demanda atendida $\mathrm{x}$ demanda não atendida & & $\mathrm{X}$ \\
\hline$\%$ de itens de medicamentos programados $\mathrm{x}$ medicamentos adquiridos & & $\mathrm{X}$ \\
\hline$\%$ de medicamentos programados $\mathrm{x}$ não utilizados & & $\mathrm{X}$ \\
\hline$\%$ de perdas de medicamentos & & $\mathrm{X}$ \\
\hline$\%$ de prescrições que atendem as exigências legais sobre prescrições & & $\mathrm{X}$ \\
\hline$\%$ de profissionais que prescrevem pela Relação de Medicamentos & & $\mathrm{X}$ \\
\hline$\%$ de redução dos custos por tratamento & & $\mathrm{X}$ \\
\hline \% de redução no número de especialidades farmacêuticas após implantação da Relação de Medicamentos & & $\mathrm{X}$ \\
\hline \multicolumn{3}{|l|}{ Qualidade de Medicamentos } \\
\hline$\%$ de produtos analisados e recusados por laboratórios de referência & & $\mathrm{X}$ \\
\hline$\%$ de produtos aprovados por análise física dos medicamentos & & $\mathrm{X}$ \\
\hline \multicolumn{3}{|l|}{ Satisfação do Usuário } \\
\hline$\%$ de receitas atendidas totalmente & & $\mathrm{X}$ \\
\hline Grau de conhecimento do usuário com relação a sua prescrição & & $\mathrm{X}$ \\
\hline Número de notificações de reações adversas & & $\mathrm{X}$ \\
\hline
\end{tabular}

Fonte: Trabalho de campo - Planejamento Estratégico Situacional e o fortalecimento da Central de Abastecimento Farmacêutico do município de Xinguara, Pará.

A ausência de indicadores de cobertura e aceitação, de eficiência, de qualidade de medicamentos e de satisfação do usuário é preocupante; pois, há que se considerar seus impactos direto sobre os processos de programação, aquisição e de distribuição, podendo gerar a perda de medicamentos, descontinuidade de tratamento, acesso comprometido devido à falta de informações das reais necessidades assistenciais (Santana, 2014; Almeida et al., 2018 \& Carvalho, 2017).

Há dificuldades limitantes relacionadas a governança da assistência farmacêutica em governos municipais. Também há carência de articulação e alinhamento entre as diversas áreas gestoras, comprometendo a concretização de algumas das ações do plano, reforçando a necessidade de mobilização de todos os gestores quanto á importância da construção conjunta para a qualificação dos serviços; em especial para o campo da Assistência Farmacêutica (Santana, 2014; Almeida et al., 2018 \& Carvalho, 2017). Preconiza-se, assim, a necessidade de se desenvolver estratégia de intervenções, a fim de se alcançar uma governabilidade efetiva e eficiente do ponto de vista organizacional, operacional e de sustentabilidade (Babar, \& Scahill, 2017; Feil \& Schreiber, 2017).

Por fim, há fortes evidências de que intervenções educativas para profissionais da saúde; em especial para profissionais farmacêuticos; assim, como aquelas que fortalecem a governança e a gestão técnica da assistência farmacêutica (Santana, 2014; Almeida et al., 2018; Carvalho, 2017). 


\section{Dificuldades, limitações e viés}

Registra-se dificuldades quanto ao acesso a dados e informações, limitação de tempo e potencial viés na revisão sistemática.

\section{Conclusão}

Quanto a "Oficina de Planejamento Estratégico Situacional da Assistência Farmacêutica do Município de Xinguara, Pará" houve ganhos significativos para a assistência farmacêutica no município de Xinguara, Pará; sendo que, a partir dos desfechos alcançados se tem conhecimento da amplitude de trabalhos que ainda precisam ser feitos.

Quanto aos produtos obtidos se apresenta a "Lista de Medicamentos Essenciais do Município de Xinguara, Pará", "Formulário Terapêutico Municipal de Xinguara, Pará: 2019" e "Procedimento Operacional Padrão: Manual de Boas Práticas da Central de Abastecimento Farmacêutico no Município de Xinguara, Pará".

Quanto as práticas de governança e gestão no nível da coordenação técnica de assistência farmacêutica, constatou-se que há distintos pontos críticos que devem ser retrabalhados; visto que há muito o que aprender e a melhorar.

Quanto ao cumprimento de indicadores relacionados ao planejamento e a gestão técnica da assistência farmacêutica (logística), observou-se que os mesmos vem sendo cumpridos. A falta de pessoal qualificado se destaca com um problema a ser prontamente resolvido. Não há registro de monitoramento e avaliação de indicadores de cobertura e aceitação, de eficiência, de qualidade de medicamentos e correlatos e de satisfação do usuário. Reconhece-se, por fim, a necessidade de intervenções que resultem na melhoria do acesso e do uso com qualidade de medicamentos; imprescindíveis para a sustentabilidade da prestação de serviços de saúde.

No processo de planejamento central da secretaria municipal de saúde não há a participação formal de profissionais farmacêuticos. Infere-se, assim, a necessidade do nível central explicitar as ações inerentes a assistência farmacêutica de modo articulado à coordenação técnica de assistência farmacêutica e vinculadas aos instrumentos de gestão do SUS; em especial a Programação Geral das Ações e dos Serviços de Saúde (PGASS), Plano Plurianual (PPA), Lei de Diretrizes Orçamentária (LDO) e Lei Orçamentária Anual (LOA). Por fim, preconiza-se implantar e implementar intervenções farmacêuticas que fortalecem a governança e a gestão técnica da assistência farmacêutica no município de Xinguara, Pará

\section{Conflitos de interesse}

Os autores registram não haver conflito de interesse.

\section{Agradecimentos}

Para a equipe multiprofissional envolvida com a assistência farmacêutica no município de Xinguara, Pará.

\section{Referências}

Almeida, A. L. G., Filho, A. J. B., Aguiar, C. S., Pessoa, D. L. R. \& Lima, S. T. G. (2018). Padronização da Relação Municipal de Medicamentos: Uma Proposta de Harmonização no Município de Ananindeua - Pará. Infinitum: Rev. Multidisciplinar. 1(1):54-68.

Amaral, S. M. S. \& Blat, C. R. (2011). Consórcio intermunicipal para a aquisição de medicamentos: impacto no desabastecimento e no custo municipal. Revista de Saúde Pública. 45(4):799-801. http://dx.doi.org/10.1590/S0034-89102011005000016.

Babar, Z. \& Scahill, S. L. (2017). Pharmaceutical policy: synthesis, themes, and future directions. In: Social and Administrative Aspects of Pharmacy in Lowand Middle-Income Countries. Ibrahim MI, Wertheimer A, Babar Z (Editors). Page Count: 484. Academic Press. http://dx.doi.org/10.1016/B978-0-12811228-1.00025-X

Brasil. (2004). Conselho Nacional de Saúde. Resolução CNS no 338 de 6 de maio de 2004. Aprova a Política Nacional de Assistência Farmacêutica. Brasília. Distrito Federal. 
Brasil. (2011). Presidência da República. Decreto nº 7.508, de 28 de junho de 2011. Regulamenta a Lei no 8.080 , de 19 de setembro de 1990, para dispor sobre a organização do Sistema Único de Saúde (SUS), o planejamento da saúde, a assistência à saúde e a articulação interfederativa, e dá outras providências. Diário Oficial da União, Brasília, DF, 29 jun. 2011.

Brasil. (2012). Congresso Nacional. Lei Complementar nº 141, de 13 de janeiro de 2012. Dispões sobre os valores mínimos a serem aplicados anualmente pela União, Estados, Distrito Federal e Municípios em ações e serviços públicos de saúde entre outras providências. Brasília. Distrito Federal.

Brasil. (2012). Conselho Nacional de Saúde (CNS). Resolução no 466 de 12 de dezembro de 2012. Aprova as diretrizes e normas regulamentadoras de pesquisas envolvendo seres humanos. Brasília. Distrito Federal.

Brasil. (2012). Ministério da Saúde. Secretaria de Ciência, Tecnologia e Insumos Estratégicos. Departamento de Ciência e Tecnologia. Diretrizes metodológicas: elaboração de revisão sistemática e metanálise de ensaios clínicos randomizados/ Ministério da Saúde, Secretaria de Ciência, Tecnologia e Insumos Estratégicos, Departamento de Ciência e Tecnologia. - Brasília: Editora do Ministério da Saúde. 92 p (Série A: Normas e Manuais Técnicos) ISBN 978-85-334-1951-3

Brasil. (2013). Ministério da Saúde. Portaria GM nº 2.135, de 25 de setembro de 2013. Estabelece diretrizes para o processo de planejamento no âmbito do Sistema Único de Saúde (SUS). Brasília. Distrito Federal.

Brasil. (2013). Tribunal de Contas da União. Referencial básico de governança/Tribunal de Contas da União. - Brasília: TCU, Secretaria de Planejamento, Governança e Gestão, Coordenação-Geral de Controle Externo dos Serviços Essenciais ao Estado e das Regiões Sul e Centro-Oeste. 57p.

Brasil. (2016). Conselho Nacional de Saúde (CNS). Resolução $n^{\circ}$ 510, de 07 de abril de 2016. Dispõe sobre as normas aplicáveis a pesquisas em Ciências Humanas e Sociais cujos procedimentos metodológicos envolvam a utilização de dados diretamente obtidos com os participantes ou de informações identificáveis ou que possam acarretar riscos maiores o que os existentes na vida cotidiana. Brasília. Distrito Federal.

Brasil. (2017). Ministério da Saúde. Portaria GM/MS nº 2.436, de 21 de setembro de 2017. Aprova a Política Nacional de Atenção Básica, estabelecendo a revisão de diretrizes para a organização da Atenção Básica, no âmbito do Sistema Único de Saúde (SUS). Brasília. Distrito Federal.

Brasil. (2017). Presidência da República. Decreto n 9.203, de 22 de novembro de 2017. Dispõe sobre a política de governança da administração pública federal direta, autárquica e fundacional. Brasília. Distrito Federal.

Carvalho, C. C. A. (2017). Papel do profissional farmacêutico no Sistema Único de Saúde (SUS) em um município de Minas Gerais. Sete Lagoas. Graduação (Trabalho de Conclusão de Curso). (Orientador) Neto, O. H. C. Faculdades Ciências da Vida. Curso de Farmácia.Minas Gerais. 26p.

Chiaroti, R., Oliveira, R. E. M. \& Ueta, J. (2017). Análise das relações municipais de medicamentos essenciais do estado de São Paulo. Espaço para a Saúde Revista de Saúde Pública do Paraná. 18(2):45-54. 10.5433/15177130-2017v18n2p45

Darosi, G. C. M. (2015). Análise da Produção Científica sobre Planejamento Estratégico Situacional (PES). Revista de Administração e Contabilidade. $7(1): 19-34$

Feil, A. A. \& Schreiber, D. (2017). Sustentabilidade e desenvolvimento sustentável: desvendando as sobreposições e alcances de seus significados. Cad. EBAPE.BR. 14(3): 667-681. http://dx.doi.org/10.1590/1679-395157473

Freitas, B. P. (2015). Caminhos do Planejamento: alternativas de reflexão e ação na contemporaneidade. Cadernos Zigmunt Bauman. 5(10):62-81. ISSN: 2236-4099

Freitas, W. R. S. \& Jabbour, C. J. C. (2011). Utilizando estudo de caso(s) como estratégia de pesquisa qualitativa: boas práticas e sugestões. Estudo \& Debate, Lajeado. 18(2), 07-22.

Gomes, E. G. M. (2009). Gestão por Resultados e eficiência na Administração Pública: uma análise à luz da experiência de Minas Gerais. São Paulo. Fundação Getúlio Vargas. Doutorado (Tese). Pós-Graduação em Administração Pública e Governo. EAESP/FGV. Transformações do Estado e Políticas Públicas. 187p.

Haby, M. M., Chapman, E., Clark, R., Barreto, J., Reveiz, L. \& Lavis, J. N. (2016). What are the best methodologies for rapid reviews of the research evidence for evidence-informed decision making in health policy and practice: a rapid review. Health Research Policy and Systems. 14. 83-95. 10.1186/s12961-016$0155-7$

Jaberidoost, M., Nikfar, S., Addollahiasl, A. \& Dinarvand, R. (2013). Pharmaceutical supply chain risks: A systematic review. DARU - Journal of Pharmaceutical Sciences. 21(69), 2-7, http://www.darujps.com/content/21/1/69

Leite, S. N., Mendes, S. J. \& Campese M. (2015). Gestão da Assistência Farmacêutica. Educação a distância. Módulo Transversal. Ed. da UFSC, 206p.

Lourenço, S. Z., Bastos, D. A. S., Guedes, C. C. R. \& Medina, F. (2018). The importance of material catalog management for the supply process - a case study. Systems \& Management. 13. 378-393. 10.20985/1980-5160.2018.v13n3.1421

Mallmann, E. M. (2015). Pesquisa-ação educacional: preocupação temática, análise e interpretação crítico-reflexiva. Cadernos de Pesquisa. 45(155), 76-98. http://dx.doi.org/10.1590/198053143088

Marcondes, N. A. V. \& Brisola, E. M. A. (2014). Análise por triangulação de métodos: um referencial para pesquisas qualitativas. Revista Univap. 20(35), 201-208.

Martins, K. O. F. (2018). Avaliação da capacidade de gestão do componente especializado da assistência farmacêutica no estado de São Paulo. São Paulo. Dissertação (Mestrado). Storpirtis, S. (Orientadora). Universidade de São Paulo: Programa de Pós-Graduação em Farmácia. 211p. São Paulo. Brasil.

Maschietto, F. (2018). Avaliação dos indicadores de estrutura, processo e resultado da assistência farmacêutica básica na região metropolitana de Campinas. Piracicaba. Dissertação (Mestrado Profissional). Universidade Estadual de Campinas: Programa de Pós-Graduação em Odontologia e Saúde Coletiva. Guerra, L.M. (Orientadora). São Paulo. Brasil. 
Matus, C. (1993). Política, planejamento e governo. Ipea, 1993. v. I e II.

Medeiros, A. L. (2018). Assistência farmacêutica no Sistema Único de Saúde: Responsabilidade compartilhada por união, estado e municípios. São Paulo. Doutorado (Tese). Faculdade de Saúde Pública da Universidade de São Paulo: Programa de Pós-Graduação em Saúde Pública. Romano-Lieber, N.S (Orientadora). São Paulo. Brasil. doi:10.11606/T.6.2018.tde-23042018-143211

Meneses, A. F. R. V., Lima, R. P., Romeu, G. A. \& Morais, A. C. L. N. (2018). Avaliação da assistência farmacêutica no Município de Ibiapina-CE. Revista Interdisciplinar em Ciências e Saúde e Biológicas - Ricsb. 2(1), 2-10, http://dx.doi.org/10.31512/ricsb.v2i1.2597

Merisio, A., Kleba, M. E., Silva, N. C. \& Kovaleski, D. F. (2012). A aquisição de medicamentos para o Sistema Único de Saúde em municípios de pequeno porte do Estado de Santa Catarina. Rev. Bras. Farm. 93(2), 173-178. https://doi.org/10.1590/1413-81232017228.18282016

Minayo, M. C. S. (2012). Análise qualitativa: teoria, passos e fidedignidade. Ciênc. Saúde Coletiva. 17(3):621-6. http://dx.doi.org/10.1590/S141381232012000300007

Mucci, C. B. M. R. \& Mafra. R. M. (2016). Pesquisa-ação e mediação dialógica como práticas metodológicas para emergência da ação comunicativa em Conselhos Gestores de Políticas Públicas. Rev. Adm. 50(1), 107-128. http://dx.doi.org/10.1590/0034-7612136991

Oliveira, D. A. \& Naves, J. O. S. (2018). Planejamento estratégico para qualificação da programação dos medicamentos para cessação do tabagismo: um relato de experiência. Tempus Actas de Saúde Coletiva. 11(3), 247-258. http://dx.doi.org/10.18569/tempus.v11i3.1847

Organização Pan-Americana da Saúde (OPAS) (2014). Manual de planejamento, execução e avaliação de projetos da Representação da OPAS/OMS no Brasil / Organização Pan-Americana da Saúde. Brasília: Organização Pan-Americana da Saúde; 62.

Pará. (2015). Fundação de Amparo à Pesquisa do Pará (Fapespa). Anuário Estatístico do Pará.

Pará. (2017). Fundação de Amparo à Pesquisa do Pará (Fapespa). Estatística municipal: Região do Araguaia.

Pará. (2018). Secretaria de Estado de Saúde Pública. Gabinete do Secretário. Portaria n ${ }^{\circ} 1095$, de 14 de novembro de 2018 . Institui a Política Estadual de Assistência Farmacêutica do Pará. Belém. Pará.

Paranhos, R., Filho, D. B. F., Rocha, E. C., Júnior, J. A. S. \& Freitas, D. (2016). Uma introdução aos métodos mistos. Sociologias. 18(4), 384-411. ISSN: 1517-4522. http://dx.doi.org/10.1590/15174522-018004221

Santana, R. S., Jesus, E. M. S. Santos, D. G., Lyra-Júnior, D. P., Leite, S. N. \& Silva, W. B. (2014). Indicadores da seleção de medicamentos em sistemas de saúde: uma revisão integrativa. Rev Panam Salud Publica. 35(3):228-34.

Santos, R. I., Farias, M. R., Pupo, G. D., Trindade, M. C. N. \& Dutra, F. F (Org.). (2016). Políticas de saúde e acesso a medicamentos. Ed. da UFSC, 224 p.

Scalercio, P. L. A. \& Czepula, A. I. S. (2017). Planejamento estratégico situacional: estudo de caso em uma farmácia básica municipal. Visão Acadêmica. $18(2), 46-54$.

Soler, O, Sinimbu, A. V., Figueiredo, D. C., Vieira, H. K. S., Galucio, N. C. R., Pinheiro, P. N. Q., Sena, S. S. I., Silva, V. G., Vieira, V. M. B. \& Ledo Y. (2018). A reorientação da assistência farmacêutica na secretaria municipal de saúde de Belém (PA): Relato de experiência. Revista Eletrônica de Farmácia. 14(4), 41-55. https://doi.org/10.5216/ref.v14i4.45427.

Soler, O. \& Maia, B. J. O. (2019). Community-level pharmaceutical interventions to reduce the risks of polypharmacy in the elderly: Overview of systematic reviews and economic evaluations. Frontiers in Pharmacology. 10. Art.302:01-12, 10.3389/fphar.2019.00302

Torres, M. R., Esher, A., Caetano, R., Pepe, V. L. E. \& Castro, C. G. S. O. (2014). Adesão às listas de medicamentos essenciais por médicos brasileiros em atuação no sistema único de saúde. Revista Brasileira de Educação Médica. 38(3), 323-330, http://dx.doi.org/10.1590/S0100-55022014000300006

Yin, R. K. (2015). Estudo de caso: planejamento e métodos. (5a ed.), Bookman. 